\title{
Production Cost and Carbon Footprint of Biomass-Derived Dimethylcyclooctane as a High Performance Jet Fuel Blendstock
}

Nawa Raj Barala,b, Minliang Yang,b, Benjamin G. Harveyc, Blake A. Simmons ${ }^{a, b}$, Aindrila Mukhopadhyay $^{\mathrm{a}, \mathrm{b}}$, Taek Soon Lee ${ }^{\mathrm{a}, \mathrm{b}}$, Corinne D. Scown*a,b,d,e

aJoint BioEnergy Institute, Lawrence Berkeley National Laboratory, Berkeley, California 94720, United States

${ }^{b}$ Biological Systems and Engineering Division, Lawrence Berkeley National Laboratory, Berkeley, California 94720, United States

'Research Department, Chemistry Division, United States Navy, Naval Air Warfare Center Weapons Division (NAWCWD), China Lake, California 93555, United States

dEnergy Analysis and Environmental Impacts Division, Lawrence Berkeley National Laboratory, Berkeley, California 94720, United States.

'Energy \& Biosciences Institute, University of California, Berkeley, Berkeley, California 94720, United States

*Corresponding author, E-mail: cdscown@lbl.gov

\begin{abstract}
Near-term decarbonization of aviation requires energy-dense, renewable liquid fuels. Biomassderived 1,4-dimethylcyclooctane (DMCO), a cyclic alkane with a volumetric net heat of combustion up to $9.2 \%$ higher than Jet-A, has the potential to serve as a low-carbon, highperformance jet fuel blendstock that may enable paraffinic bio-jet fuels to operate without aromatic compounds. DMCO can be produced from bio-derived isoprenol (3-methyl-3-buten-1ol) through a multi-step upgrading process. This study presents detailed process configurations for DMCO production to estimate the minimum selling price and life-cycle greenhouse gas (GHG) footprint considering three different hydrogenation catalysts and two bioconversion pathways. The platinum-based catalyst offers the lowest production cost and GHG footprint of $\$ 9.0 /$ L-Jet-A $A_{\text {eq }}$ and 61.4 gCO$_{2 \mathrm{e}} / \mathrm{MJ}$, given the current state of technology. However, when the conversion process is optimized, hydrogenation with a Raney nickel catalyst is preferable, resulting in a $\$ 1.5 / \mathrm{L}-J$ et- $\mathrm{A}_{\text {eq }}$ cost and $18.3 \mathrm{gCO}_{2 \mathrm{e}} / \mathrm{MJ} \mathrm{GHG}$ footprint if biomass sorghum is the feedstock. This price point requires dramatic improvements, including 28 metric-ton/ha sorghum yield and $95-98 \%$ of the theoretical maximum conversion of biomass-to-sugars, sugars-to-isoprenol, isoprenol-to-isoprene, and isoprene-to-DMCO. Because increased gravimetric energy density of jet fuels translates to reduced aircraft weight, DMCO also has the potential to improve aircraft efficiency, particularly on long-haul flights.
\end{abstract}


Keywords: biomass sorghum; ionic liquid; lignocellulosic sugar; isoprenol; sustainable aviation fuel; techno-economic analysis; life-cycle assessment

\section{Graphic for Table of Contents (TOC)/Abstract Art}

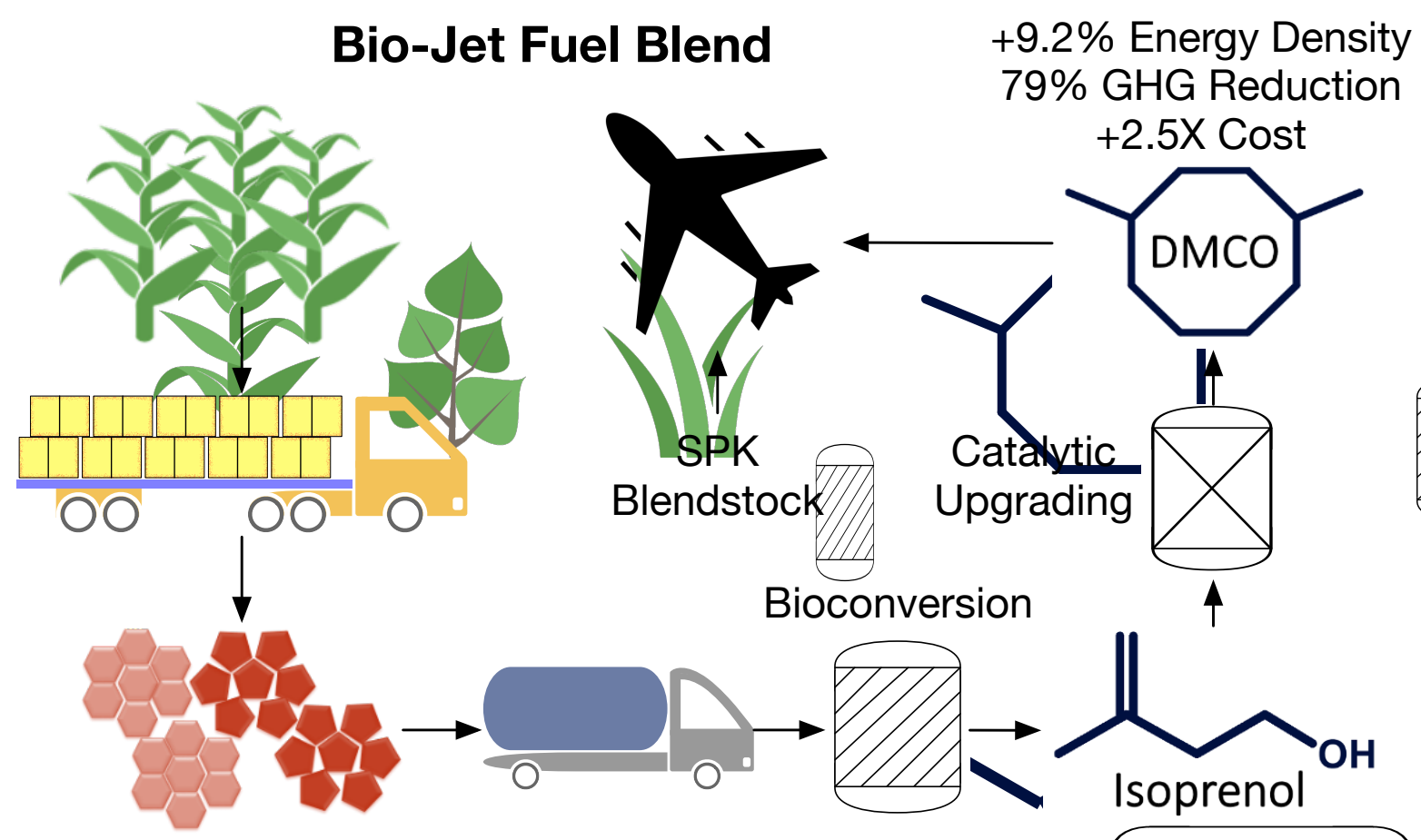




\section{Introduction}

The aviation industry is difficult to decarbonize in part because of aircraft weight constraints, and the difficulty of developing batteries with sufficient pack-level specific energy. ${ }^{1}$ Energydense liquid fuels are likely to play an important role in fueling large aircraft for the foreseeable future and numerous routes have been developed to bio-based blendstocks suitable for use in Jet-A. ${ }^{2,3}$ However, bio-jet fuel uptake is limited by a few key factors: first, currently available bio-jet blendstocks are paraffinic, and Jet-A relies on aromatic blendstocks to ensure o-ring/seal swelling; ${ }^{4}$ second, the properties of bio-based blendstocks are not sufficiently advantageous to catalyze demand in early-adopter markets that value performance over cost. ${ }^{2,5}$ The ability to appeal to early-adopters that prioritize performance over cost is essential, as bio-jet fuels have not yet reached cost-parity with Jet-A without policy support. ${ }^{2}$ While paraffins present in hydroprocessed esters and fatty acids (HEFA) and other more mature bio-jet fuels provide modest increases in the gravimetric net heat of combustion, they cannot currently serve as a one-to-one replacement for Jet-A. The aromatic compounds typically added for o-ring/seal swelling, however, present downsides: these molecules initiate the formation of carcinogenic polyaromatic hydrocarbons ${ }^{6}$ and reduce the net heat of combustion for the overall fuel blend. In this paper, we evaluate the cost and environmental tradeoffs of producing a bio-derived, energy-dense naphthene potentially capable of replacing these aromatic constituents: 1,4dimethylcyclooctane (DMCO).

Cyclic alkanes such as DMCO have been shown to achieve acceptable swelling of nitrile o-rings at a $30 \%$ blending level as compared to a conventional jet fuel with $8 \%$ aromatics. ${ }^{4}$ DMCO's cyclic structure and chain branching lends the molecular exceptional fuel properties, including a 
density of $0.827 \mathrm{~kg} / \mathrm{L}$ ( $6.7 \%$ higher than Jet-A), a gravimetric net heat of combustion of 43.82 $\mathrm{MJ} / \mathrm{kg}(2.4 \%$ higher than Jet-A), and a volumetric net heat of combustion of $36.22 \mathrm{MJ} / \mathrm{L}(9.2 \%$ higher than Jet-A). ${ }^{6}$ DMCO also has a lower kinematic viscosity $\left(4.17 \mathrm{~mm}^{2} / \mathrm{s}\right)$ and freezing point $\left(<-78^{\circ} \mathrm{C}\right)$ as well as an acceptable flash point $\left(50^{\circ} \mathrm{C}\right)$ relative to the conventional jet fuel. ${ }^{6}$ Ultimately, the success of this advanced jet fuel blendstock will depend on the cost of production, its ability to reduce greenhouse gas (GHG) emissions relative to petroleum-derived jet fuel, and use-phase benefits associated with its favorable fuel properties.

DMCO can be catalytically produced from isoprene in two steps: dimerization and subsequent hydrogenation (Fig. 1). ${ }^{6}$ There are numerous routes to produce the precursor isoprene; it is the monomer of natural rubber and can also be produced from sugars in E. coli through the MVA or MEP pathways. ${ }^{7,8}$ However, the volatile isoprene product is challenging to recover and purify for downstream conversion; it is also highly flammable, which increases the risk of fire or explosion in an aerobic bioreactor. To avoid this issue, isoprene can also be produced from the dehydration of isoprenol (3-methyl-3-buten-1-ol) and this is the route explored further in this paper. ${ }^{9,10}$ Other isoprene production methods are documented in the Supporting Information (SI)-S2. Isoprenol can be biologically produced from plant-derived sugars by using microbes such as Escherichia coli. ${ }^{11,12}$ E. coli metabolizes sugars, such as glucose and xylose, resulting in isoprenol yields from 10.5 to $22.3 \mathrm{~g}$ per $100 \mathrm{~g}$ of glucose using different biosynthetic pathways including the mevalonic acid (MVA) pathway and 5-methyl erythritol phosphate (MEP) pathway. ${ }^{12,13}$ This highest demonstrated isoprenol yield is $55 \%$ of the maximum stoichiometric theoretical yield of $40.9 \mathrm{~g}$ per $100 \mathrm{~g}$ of glucose. ${ }^{14}$ The detailed costs, life-cycle GHG emissions, and water footprint for isoprenol produced from biomass sorghum have been documented in 
recent study. ${ }^{14}$ Isoprenol is also potentially interesting as a product for use in multiple markets; it is easily transportable in liquid form and, in addition to its potential for conversion to isoprene, it can also be used directly as a gasoline blendstock. ${ }^{14}$

Recently, researchers dimerized isoprene into 1,6-dimethyl-1,5-cyclooctadiene (DMCOD) using earth-abundant iron-based catalysts (Fig. 1)..$^{6,15}$ They obtained an isolated DMCOD yield of 92\% at a catalyst-loading rate of $0.025 \mathrm{~mol} \%$. DMCOD requires subsequent hydrogenation in the presence of a catalyst to produce DMCO (Fig. 1). The same group has demonstrated an isolated yield of DMCO from DMCOD of 85 wt\% with $\mathrm{PtO}_{2}$ catalyst. ${ }^{6}$ In more recent work, researchers have demonstrated DMCOD-to-DMCO yields of 97 wt\%, 75 wt\%, and 94 wt\%, respectively, with three different metal catalysts $-\mathrm{PtO}_{2}$, Raney nickel, and $10 \% \mathrm{Pd} / \mathrm{C}$. These results are encouraging, but overall production cost and life-cycle GHG reduction potential relative to petroleum fuels will determine the degree to which DMCO can serve as a jet fuel blendstock. This study provides a detailed techno-economic analysis (TEA) and life-cycle GHG inventory for bio-based DMCO production using biomass sorghum as a feedstock. We explore two different biosynthetic routes to the isoprenol precursor-the MVA and MEP pathways - and three different hydrogenation catalysts $-10 \% \mathrm{Pt} / \mathrm{C}$, Raney nickel, and $10 \% \mathrm{Pd} / \mathrm{C}$. Although $\mathrm{PtO}_{2}$ was used for experimental research, commercial production would likely use a cheaper carbonsupported platinum catalyst $(10 \% \mathrm{Pt} / \mathrm{C})$ so our model relies on the assumption that the carbonsupported platinum catalyst achieves comparable performance. We identify the most significant process parameters and identify potential avenues to reducing the minimum selling price to $\$ 0.66 / \mathrm{L}(\$ 2.5 / \mathrm{gal})$ and achieving at least a $60 \%$ GHG reduction relative to the conventional jet fuel. 


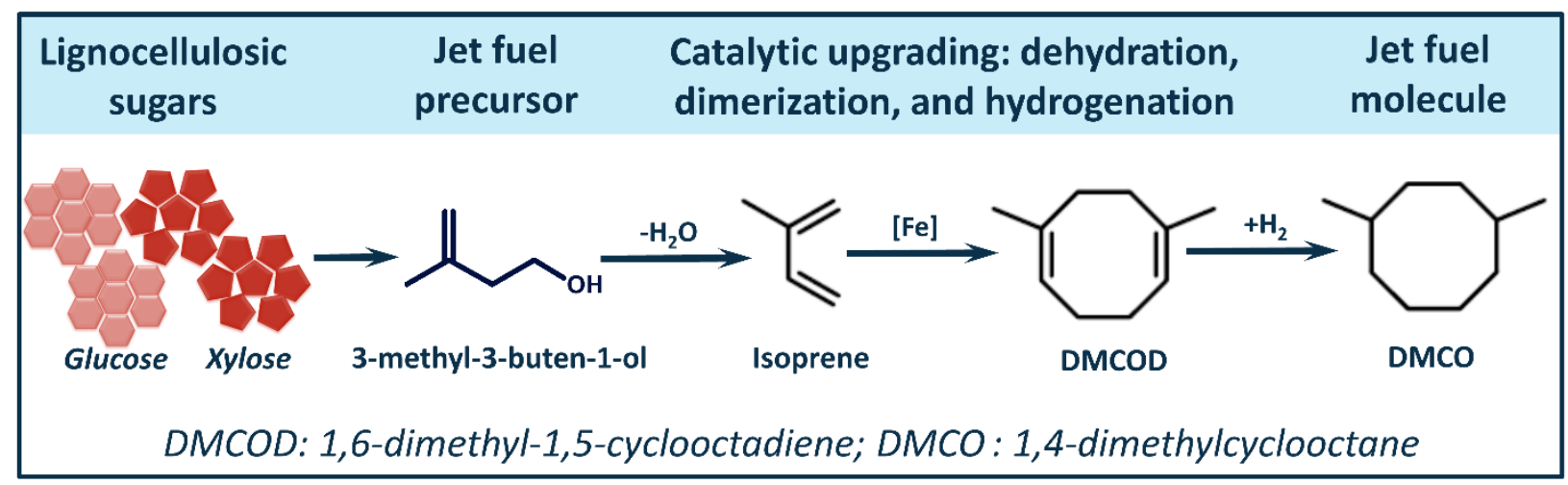

Fig. 1 An overview of 1,4-dimethylcyclooctane (DMCO) synthesis processes from the biomassderived glucose and xylose

\section{Methods}

\subsection{Process Model for DMCO Production}

This study considers separate sugar production depots, which ship lignocellulosic sugars for further conversion at large-scale biorefineries. The modeled DMCO production facility utilizes 1000 bone-dry metric tons (bdt) of lignocellulosic sugar per day (more detail on biorefinery economies of scale are provided in the SI-Fig. S1). This strategy allows for a decoupling of the sugar production process from downstream biological conversion and upgrading, allowing biorefineries the flexibility to source sugar from different sources depending on availability and price. Although this paper focuses on cellulosic sugars derived from biomass sorghum, the modeled DMCO production facilities could choose to source some or all of their sugars from first-generation feedstocks. In the baseline scenario, the biorefinery is co-located with the sugar 
production facility (the supply distance of sugar is zero). We also explore scenarios in which sugar must be shipped longer distances from remote depot facilities.

The lignocellulosic sugar considered in this study is derived from field-dried biomass sorghum via a one-pot high-gravity ionic liquid (cholinium lysinate, [Ch][Lys]) based biomass deconstruction process. ${ }^{16}$ The incoming sugar composition for the baseline scenario is $70 \%$ glucose and $30 \%$ xylose. ${ }^{17}$ This sugar composition was determined from a separate sugar model, using the current state-of-the-art biomass sorghum-to-sugar conversion rate. ${ }^{17} \mathrm{At}$ present, about $2500 \mathrm{bdt}$ of biomass sorghum is required to produce $1000 \mathrm{bdt}$ of cellulosic sugar. Our recent studies ${ }^{14,17}$ documented the detailed modeling parameters and assumptions associated with the sugar production process and the results are documented in Table 1 and SIFig. S2. Briefly, the sugar model is based on an estimated sorghum bale supply cost of $\$ 125 / \mathrm{bdt}$ and associated GHG emissions of $112 \mathrm{kgCO}_{2 \mathrm{e}} / \mathrm{bdt}$ at the pretreatment reactor throat, which are consistent with our recent study. ${ }^{19}$ The structural carbohydrate and lignin contents of biomass sorghum for the baseline sugar model were estimated at $52 \%$ and $22 \%$, respectively. ${ }^{14}$ The total carbohydrate content in biomass was increased to a maximum of $70 \%$ and the lignin fraction was reduced to $9.8 \%$ for the optimal future case. ${ }^{14}$ Additionally, we considered the experimentally determined glucose and xylose yields of $75.8 \%$ and $60.7 \%$, respectively, at an IL loading rate of $5 \%$ and enzyme loading rate of $30 \mathrm{mg}$-protein/g-glucan for the baseline scenario. ${ }^{17}$ Although this paper considers dry sorghum, a recent study has shown that using ensiled sorghum can increase sugar yields at lower IL loading and may be preferable in some cases. ${ }^{17}$ For the optimal future case, the sugar yield was increased to $93 \%$ of the theoretical 
yield, and IL and enzyme loading rates were reduced to $2.5 \%$ and $10 \mathrm{mg}$-protein/g-glucan, respectively. ${ }^{14,17}$

Once delivered to the biorefinery, the lignocellulosic sugar is routed to the aerobic bioconversion reactor for isoprenol production. The fundamental unit operations involved in isoprenol production do not vary depending on the choice between MVA and MEP biosynthetic pathways; titer, rate, and yield variations between these pathways will primarily impact the sizing and residence time for the bioconversion reactor. ${ }^{7}$ Full details of the isoprenol production process from biomass sorghum feedstock are documented in our recent study. ${ }^{14}$ Air is supplied using a compressor to meet the required oxygen for the cell redox balancing, which varies depending on the biosynthetic pathway (Table 1). The bioconversion reactor is operated at $30^{\circ} \mathrm{C}$ for $63 \mathrm{~h} .{ }^{12}$ Table 1 summarizes the glucose and xylose utilization rates and the reaction stoichiometry for each pathway considered for analysis in this study. An important note is that isoprenol production has currently been demonstrated only in hosts that utilize glucose. However, we adjust the state of technology (SOT) scenario to account for the likelihood that, in a commercial scale operation, a co-utilizing strain would be used to convert both glucose and xylose. We slightly lower xylose utilization (10\% lower than glucose). Additionally, we calculate the production cost and carbon footprint of DMCO if only glucose is utilized as an alternative scenario. Following bioconversion, the solid fraction, such as cell mass, is separated by using a decanter centrifuge and routed to the onsite energy generation unit, and the liquid fraction is sent to the isoprenol recovery and separation unit. Isoprenol is recovered through the distillation and decantation system, which is further purified using a subsequent distillation. The overall isoprenol loss during the recovery and separation process is assumed to be $5 \%$. 
After recovery and separation, isoprenol is routed to the catalytic upgrading unit and the remaining liquid fraction is delivered to the wastewater treatment unit.

In the catalytic upgrading unit, isoprenol is dehydrated to produce isoprene, which is subsequently dimerized to DMCOD, and DMCOD is hydrogenated to produce DMCO. In this unit, isoprenol is first mixed with steam $\left(20\right.$ vol\% at $\left.150^{\circ} \mathrm{C}\right)$ and catalytic dehydration is carried out using phosphoric acid (15 wt\% based on the whole slurry). ${ }^{10}$ The yield of isoprene is assumed to be $95 \%$ of the theoretical yield. ${ }^{10}$ Isoprene is recovered via condensation, where $3 \%$ of isoprene is lost during the process. The recovered isoprene after the dehydration process is delivered to the dimerization reactor.

The dimerization of isoprene is carried out in the presence of an iminopyridine iron dihalide catalyst, $\left[\left({ }^{\mathrm{MePI}}\right) \mathrm{FeCl}(\mu-\mathrm{Cl})\right]_{2}$, at room temperature for $24 \mathrm{~h} .{ }^{6}$ The reaction is activated by adding a $\mathrm{MeMgCl}$ solution. The isolated yield of DMCOD is $92 \mathrm{wt} \%{ }^{6}$ This alkene can be hydrogenated to form DMCO in the presence of one of three different metal catalysts: $\mathrm{PtO}_{2}$ (or $10 \% \mathrm{Pt} / \mathrm{C}$ ), Raney nickel, and $10 \% \mathrm{Pd} / \mathrm{C}$. Excess hydrogen is recovered and $91 \%$ of the recovered hydrogen is recycled back to the hydrogenation unit. The DMCO is purified by using distillation and then stored on-site. The waste hydrogen is routed to the onsite energy generation unit and other wastes from the catalytic upgrading unit are delivered to the wastewater treatment unit. Additional details of the catalytic upgrading of isoprene into DMCO is available elsewhere. $6,18,19$ Table 1 summarizes the key operating parameters and ranges explored in this study. 
Table 1. Major input parameters associated with the DMCO production stages under different scenarios

\begin{tabular}{|c|c|c|c|c|}
\hline Parameter & Unit & $\begin{array}{l}\text { Current state } \\
\text { of technology }\end{array}$ & $\begin{array}{l}\text { Improved MVA } \\
\text { or MEP pathway }\end{array}$ & $\begin{array}{c}\text { Optimal future } \\
\text { case }\end{array}$ \\
\hline \multicolumn{5}{|l|}{ Lignocellulosic sugar feedstock } \\
\hline Cost of sugar ${ }^{\beta}$ & $\$ / \mathrm{t}$ & 618.5 & 618.5 & 220.9 \\
\hline Glucose $e^{\beta}$ & $\%$ & 70.4 & 70.4 & 61.60 \\
\hline Xylose $e^{\beta}$ & $\%$ & 29.6 & 29.6 & 38.40 \\
\hline Impacts from SOC sequestration $\mathrm{n}^{\beta, 20,21}$ & $\mathrm{kgCO}_{2 \mathrm{e}} / \mathrm{kg}$ & -0.11 & -0.11 & -0.11 \\
\hline Carbon footprint of sugar excluding SOC $^{\beta}$ & $\mathrm{kgCO}_{2 \mathrm{e}} / \mathrm{kg}$ & 0.17 & 0.17 & 0.08 \\
\hline \multicolumn{5}{|l|}{ Bioconversion } \\
\hline Solid loading rate 22 & $w t \%$ & 25 & 25 & 25 \\
\hline Bioreactor power consumption 2,22 & $\mathrm{kW} / \mathrm{m}^{3}$ & 0.56 & 0.56 & 0.11 \\
\hline Bioconversion time ${ }^{12}$ & $\mathrm{~h}$ & 63 & 36 & 36 \\
\hline Glucose utilization 12 & $\%$ & 44 & 95 & 98 \\
\hline Xylose utilization ${ }^{\mathrm{Y}, 12}$ & $\%$ & 39.6 & 85 & 95 \\
\hline \multicolumn{5}{|l|}{ Recovery and separation } \\
\hline Recovery of isoprenol ${ }^{v}$ & $\%$ & 95 & 95 & 98 \\
\hline \multicolumn{5}{|l|}{ Catalytic upgrading } \\
\hline Isoprenol to isoprene conversion rate 9,10 & $\%$ & 95 & 95 & 98 \\
\hline Dimerization catalyst loading rate & $w t \%$ & $0.13^{\omega}$ & $0.13^{\omega}$ & $0.0013^{\gamma}$ \\
\hline Dimerization catalyst loading $\operatorname{cost}^{v 23}$ & $\$ / \mathrm{kg}$ & 10.26 & 10.26 & 7.14 \\
\hline Isoprene to DMCOD isolated yield ${ }^{6}$ & $\%$ & 97 & 97 & $98^{v}$ \\
\hline \multicolumn{5}{|l|}{ Hydrogenation with $10 \% \mathrm{Pt} / \mathrm{C}$} \\
\hline $10 \% \mathrm{Pt} / \mathrm{C}$ catalyst loading ${ }^{\omega}$ & $w t \%$ & 0.75 & 0.75 & 0.75 \\
\hline $10 \% \mathrm{Pt} / \mathrm{C}$ catalyst cost ${ }^{23}$ & $\$ / \mathrm{kg}$ & 261.3 & 261.3 & 231.8 \\
\hline DMCOD to DMCO isolated yield & $w t \%$ & $97^{\omega}$ & $97^{\omega}$ & $98^{v}$ \\
\hline \multicolumn{5}{|l|}{ Hydrogenation with Raney Ni } \\
\hline Raney Ni catalyst loading $\omega$ & $w t \%$ & 0.43 & 0.43 & 0.43 \\
\hline Raney Ni catalyst cost 23 & $\$ / \mathrm{kg}$ & 14.5 & 14.5 & 10.5 \\
\hline DMCOD to DMCO isolated yield & $w t \%$ & $75^{\omega}$ & $75^{\omega}$ & $98^{v}$ \\
\hline \multicolumn{5}{|l|}{ Hydrogenation with $10 \% \mathrm{Pd} / \mathrm{C}$} \\
\hline $10 \% \mathrm{Pd} / \mathrm{C}$ catalyst loading ${ }^{\omega}$ & $w t \%$ & 1 & 1 & 1 \\
\hline $10 \% \mathrm{Pd} / \mathrm{C}$ catalyst cost ${ }^{23}$ & $\$ / k g$ & 316.2 & 316.2 & 279.8 \\
\hline DMCOD to DMCO isolated yield & wt\% & $94^{\omega}$ & $94^{\omega}$ & $98^{\nu}$ \\
\hline
\end{tabular}

Bioconversion reactor (stoichiometry)

MVA pathway: maximum pathway dependent theoretical yield of isoprenol $=31.87 \mathrm{~g} / 100 \mathrm{~g}$ of sugar

1.5 Glucose +2 Oxygen $=1$ Isoprenol $+4 \mathrm{CO}_{2}+4 \mathrm{H}_{2} \mathrm{O}$

1.8 Xylose +2 Oxygen $=1$ Isoprenol $+4 \mathrm{CO}_{2}+4 \mathrm{H}_{2} \mathrm{O}$

MEP pathway: maximum pathway dependent theoretical yield of isoprenol $=38.25 \mathrm{~g} / 100 \mathrm{~g}$ of sugar

1.25 Glucose +0.5 Oxygen $=1$ Isoprenol $+2.5 \mathrm{CO}_{2}+2.5 \mathrm{H}_{2} \mathrm{O}$

1.5 Xylose +0.5 Oxygen $=1$ Isoprenol $+2.5 \mathrm{CO}_{2}+2.5 \mathrm{H}_{2} \mathrm{O}$

$M V A=$ mevalonic acid pathway; and MEP = 5-methyl erythritol phosphate pathway; SOC = Soil organic carbon; $D M C O D=1,6$-dimethyl-1,5-cyclooctadiene; and DMCO = 1,4-Dimethylcyclooctane.

${ }^{\beta}$ Determined in a separate sugar model (SI-Fig. S2). ${ }^{\vee}$ Assumed for analysis in this study. ${ }^{\omega}$ Experimental data obtained from Naval Air Warfare Center Weapons Division, China Lake, California. 
The wastewater treatment, onsite energy generation, and utility stages considered in this study

(Fig. 1) are consistent with previously published technoeconomic analyses. ${ }^{22,24}$ Supplemental natural gas is added to the boiler because the fuel generated from the unutilized sugars (biogas produced through anaerobic digestion) and the waste hydrogen is not sufficient to meet the heat and electricity demands of the facility. The lignin fraction of biomass is separated and combusted at the sugar production facility to generate process steam and electricity, and thus it is not available for combustion at the DMCO production facility modeled here. Cost and carbon credits from the lignin-fired electricity generation are accounted for in the standalone sugar model, which are reflected in the sugar production cost and associated GHG emissions (Table 1).

\subsection{Determination of Minimum Selling Price and GHG Emissions}

The minimum selling price of DMCO is determined using the standard discounted cash flow rate of return analysis, which is consistent with previous studies. ${ }^{14,22}$ Briefly, the capital and operating costs are determined based on the process model developed in SuperPro Designer after the rigorous material and energy balancing and sizing of the process equipment. The baseline equipment purchase costs are gathered from recent TEA studies. ${ }^{2,22,24}$ The SuperPro model captures changes in the material flows, equipment size and quantity, and corresponding changes in the capital and operating costs. We considered an internal rate of return (IRR) of $10 \%$, plant lifetime of 30 years, and plant operating hours of 7920 h (330 days/year and 24 
h/day). ${ }^{14,22}$ The income tax is assumed to be $21 \%^{8}$ to accurately reflect the most recent corporate tax rate. ${ }^{22}$

The carbon footprint of DMCO is determined using the Bio-Cradle-to-Grave (BioC2G) model used in previous studies. ${ }^{25}$ The model uses a hybrid process-based/input-output-based lifecycle inventory approach and most emission factors (SI-Table S3) are harmonized with Argonne National Lab's Greenhouse Gases, Regulated Emissions, and Energy Use in Technologies (GREET) model. The material and energy balances for fuel production are obtained from the SuperPro model serve as the main input to the LCA model. The GHG emissions impact vector of process chemicals were gathered from widely used LCA databases. ${ }^{26-28}$ We use the U.S. electricity mix for the sugar production facility and DMCO biorefinery. Carbon footprints of the selected metal catalysts were determined by building their separate production process models and using all the direct/indirect inputs to the model. The resulting carbon footprints are documented in the SI-Table S3. The carbon footprint of tetrahydrofuran (THF) ${ }^{29}$ is used for $\mathrm{MeMgCl}$ because it is available as a solution in THF (3.0 M in THF). We consider the DMCO higher heating value to be $46.3 \mathrm{MJ} / \mathrm{kg}$ (SI-Table S1) and the functional unit of $1 \mathrm{MJ}$. 


\subsection{Scenario and Uncertainty Analysis}

Each part of the conversion process, from breakdown of biomass to sugars, to biological conversion of sugars to isoprenol and final conversion to DMCO are all under active research and development. To reflect the potential outcome of ongoing efforts in engineering MVA and MEP biosynthetic pathways to improve the titer, rate, and yield of isoprenol, ${ }^{30-32}$ we present future scenarios based on $95 \%$ of the pathway-dependent maximum theoretical yield of isoprenol. The current yield scenario reflects the current state of the art of the technology considering the currently demonstrated average yield of isoprenol via the most common MVA pathway. ${ }^{12,13}$ Apart from the glucose and xylose utilization rates, aeration rate, and bioconversion time, other input parameters remained the same for these different product yield scenarios (Table 1). In an optimal future case, we model the minimum selling price and life-cycle GHG footprint of DMCO considering $95-98 \%$ of the theoretical yield and otherwise optimized performance for each stage of the process, including biomass composition/cost, deconstruction, bioconversion, and upgrading (Table 1).

Even within each scenario, there are sources of uncertainty that will impact the minimum selling price and life-cycle GHG footprint of DMCO (SI-Table S2). While the individual uncertainty determines the relative impact of each input parameter, the uncertainty including all the input parameters reflects the overall impact due to their variabilities. The stochastic sensitivity analysis was performed by modeling all inputs with the uniform probability distribution. We further determined the overall uncertainties in selling price and GHG emissions. Baseline, minimum, and maximum values used to model input parameters are 
summarized in the SI-Table S2. For the uncertainty analysis, sugar composition, sugar

utilization, and the DMCOD to DMCO conversion rate considered for each scenario (Table 1)

were kept constant. Other inputs were modeled based on their probability distributions, including uniform, triangular, and lognormal (SI-Tables S2). For the optimal scenario, an ideal value assigned for each parameter (Table 1) was considered as a baseline value, which resulted in positively skewed probability distributions of most of the key inputs. The simulation ran for 5000 Monte Carlo trials.

\subsection{Fuel Cost Saving in a Commercial Flight}

Fuel consumption of an aircraft over the flown distance was determined using the Breguet range equation illustrated in previous studies. ${ }^{33,34}$ The main inputs to the Breguet range equation can be obtained from a payload range diagram of an aircraft, which is presented in the SI (Fig. S3). The payload range diagram provides the maximum possible take-off mass based on the planned flight distance. Other inputs to the Breguet range equation, including aircraft characteristics (SI-Table S5) as well as density and lower heating values of conventional jet fuel and DMCO (SI-Table S1) are summarized in the SI. A previous study ${ }^{33}$ documented the detailed methods and illustrated each calculation step with an example. Briefly, the Breguet range equation provides fuel consumption per passenger per $100 \mathrm{~km}$ flight distance over the flown distance. The fuel cost is determined considering the fuel consumption over the range obtained from the Breguet range equation and the prices of Jet-A and DMCO. We considered the projected prices (2020 U.S. dollars) of conventional jet fuel at the refinery gate in 2050 of $\$ 0.42 / \mathrm{L}, \$ 0.73 / \mathrm{L}$, and $\$ 1.22 / \mathrm{L}$, which correspond to the low, reference, and high oil prices. ${ }^{35}$ 
Fuel cost savings over conventional jet fuel were determined by considering the optimal selling price of DMCO at the biorefinery gate of $\$ 1.46 / L-J e t-A_{\text {eq. }}$. We consider an example flight from San Francisco (SFO), USA to London (LHR), UK (a distance of 4664 nautical miles or $8638 \mathrm{~km}$ ) to illustrate the total fuel savings over the entire flight range. Additionally, the impacts of policy incentives on the fuel cost saving were determined considering California's Low Carbon Fuel Standard (LCFS) credit and the Renewable Fuel Identification Number (RIN) values. These credits reduce the minimum selling price of DMCO. The LCFS (assigned based on carbon intensity) and RIN values (for D3 category fuels) considered in this study are summarized in the SI-Table S4.

\section{Results and Discussion}

\subsection{Minimum Selling Price of DMCO}

Fig. 2 depicts the minimum selling prices of DMCO under current and potential future scenarios, including improved isoprenol yields and optimal conditions for other processes. Broadly speaking, DMCO results in a higher minimum selling price than paraffinic bio-jet fuels currently on the market, such as HEFA synthetic paraffinic kerosene (SPK), alcohol-to-jet SPK, or FischerTropsch SPK. Improvements at each step of the process will be required to reach the lowest possible cost, excluding policy incentives, of $\$ 1.5 /$ L-Jet-A $A_{\text {eq. }}$ Optimizing the titer, rate, and yield for isoprenol is an important first step. Research in recent years on isoprenol biosynthesis has mainly focused on different MVA pathways, including the native and IPP-bypass MVA pathways, to improve titer, rate, and yield. ${ }^{6,10}$ The experimentally demonstrated isoprenol yield via the 
MVA pathway, on average, of $14 \mathrm{~g} / 100-\mathrm{g}$ of sugar ${ }^{12}$ and the overall isoprenol-to-DMCO conversion rates of $51-66$ wt\% ${ }^{6,10}$ result in a minimum selling price of DMCO of $\$ 9.0, \$ 11$, and \$9.9 per L-Jet-A eq with 10\%Pt/C, Raney nickel, and 10\%Pd/C catalysts, respectively (Fig. 2-a). These current state-of-the-art selling prices of DMCO are increased by $29-34 \%$ when only glucose is utilized (Fig. 2-a) because isoprenol production utilizing xylose or lignocellulosic hydrolysate is not fully demonstrated. Based on the Monte Carlo simulation results, the likelihoods of achieving minimum selling prices at or below these values are in the range of 4548\% (Fig. 2-a). Variation in minimum selling price across the catalyst options are the result of differing isoprenol-to-DMCO conversion rates and the catalyst loading rates and unit costs (Table 1). The minimum selling prices corresponding to the current state-of-the-art are still an order of magnitude higher than the last 10-year (2010-2019) average price of jet fuel at the refinery gate of $\$ 0.6 / \mathrm{L}-$ Jet-A. ${ }^{36}$ The cellulosic sugar costs and catalytic upgrading processes are responsible for $80-83 \%$ of the total DMCO production cost, so reducing sugar costs, improving isoprenol yield, and increasing DMCO yields from DMCOD are particularly critical to reaching cost-competitiveness (Figure 2-a).

Both the MVA and MEP pathways could be considered for isoprenol synthesis in the future to improve the sugar to DMCO conversion rate. The MEP biosynthetic pathway results in a 9.7 to $13 \%$ lower selling price of DMCO relative to the MVA pathway when both pathways are improved to achieve $90 \%$ of the theoretical yield (Fig. 2- b and c). The MEP pathway has an advantage because of its $20 \%$ higher theoretical isoprenol yield from both glucose and xylose relative to MVA, and a lower oxygen requirement for the cell redox balancing (Table 1). However, the MEP pathway is difficult to control relative to the MVA pathway because any 
imbalances in the supply of glyceraldehyde 3-phosphate and pyruvate greatly decrease the pathway performance.

The pathway-dependent selling prices of DMCO (Fig. 2-b and c) at $90 \%$ of theoretical isoprenol yield suggest that focusing solely on improving the titer, rate, and yield of isoprenol is not sufficient to achieve a market-competitive price for DMCO. Further optimization of the MVA pathway to achieve $96.7 \%$ of the pathway dependent theoretical yield (Table 1 ) or $75.4 \%$ of the stoichiometric maximum theoretical yield of $40.9 \mathrm{wt} \%$ is required. This high biological yield is considered assuming that the engineered E. coli strain directs most lignocellulosic sugars to isoprenol and $\mathrm{CO}_{2}$ production (Table 1 ) and only $2 \%$ of lignocellulosic sugar to the cell mass growth, similar to Z. mobilis. ${ }^{22}$ Additionally, optimal values of major process parameters (Table 1) are required. In particular, improving the isoprenol-to-DMCO conversion rate to $77 \%$ and reducing lignocellulosic sugar production cost to $\$ 221 /$ bdt result in a minimum selling price of DMCO in the range of $\$ 1.5-2.6 /$ L-Jet-A $A_{\text {eq }}$ (Fig. 2-d). Based on the Monte Carlo simulation, the likelihoods of achieving these optimal prices (Fig. 2-d) are $22 \%$ with Raney nickel, $8 \%$ with $10 \% \mathrm{Pt} / \mathrm{C}$, and $7 \%$ with $10 \% \mathrm{Pd} / \mathrm{C}$ catalysts. These likelihoods can be increased by optimizing and/or fixing (assuming no variabilities) the key cost drivers (Fig. 3 and SI-Fig S4), including lignocellulosic sugar production cost, solids loading rate, glucose and xylose utilization, and the isoprenol to DMCO conversion rate at their optimal values. For comparison, the results from past studies ${ }^{2,34}$ considering different biochemical and thermochemical jet fuel conversion pathways are in the range of $\$ 0.6-9.8 / \mathrm{L}-\mathrm{Jet}-\mathrm{A}_{\text {eq }}$ and the calculated average value is $\$ 2.1 / \mathrm{L}-\mathrm{Jet}-$ $A_{\text {eq. }}$ This average selling price of bio-jet fuel is close to the optimal selling price of DMCO 
estimated in this study; however, these studies all rely on different assumptions, including feedstock types and delivered costs, conversion processes, and biorefinery configurations.
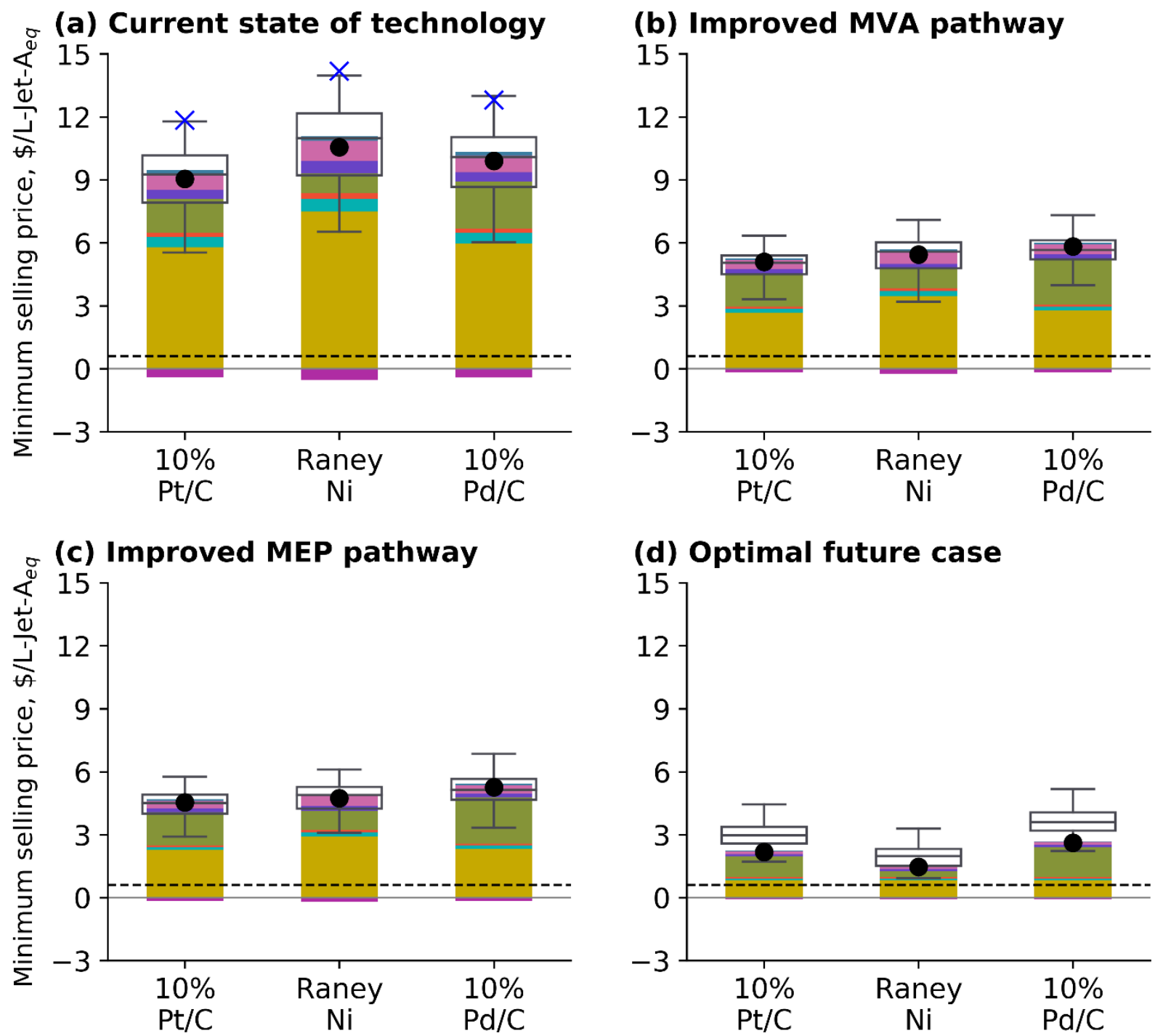

(d) Optimal future case

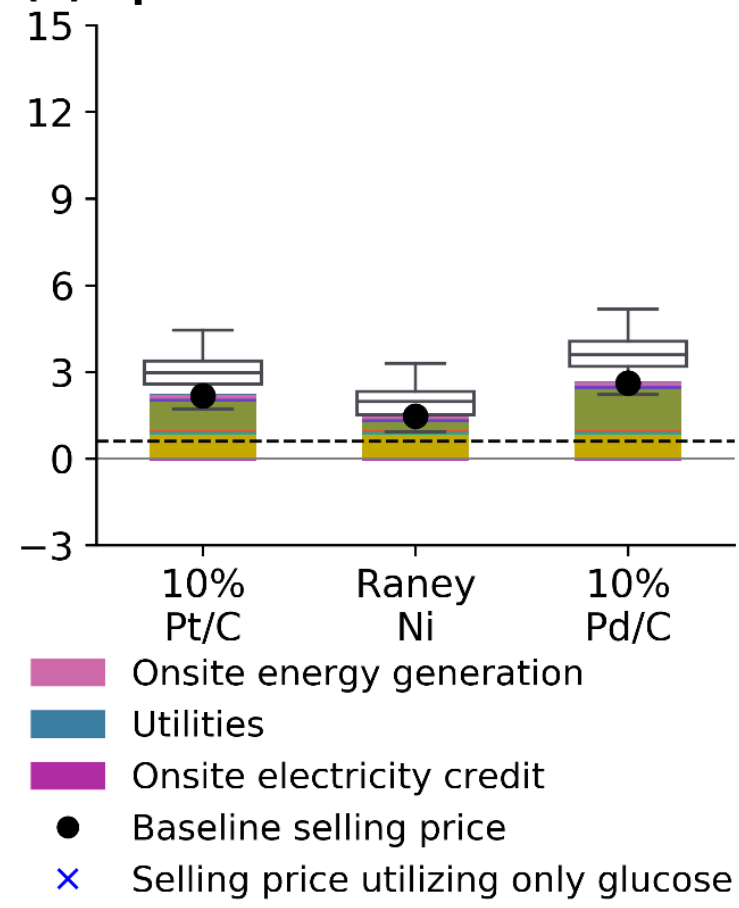

Fig. 2 Minimum selling price of DMCO under different scenarios: (a) current state-oftechnology (SOT) with MVA pathway; (b) Improved MVA pathway with $90 \%$ of the theoretical isoprenol yield; (c) Improved MEP pathways with $90 \%$ of the theoretical isoprenol yield; and (d) Optimal future case with MVA pathway. The catalytic upgrading costs estimated in this study of 
$\$ 0.3-1.5 /$ L-Jet-A $A_{\text {eq }}$ is similar to the alcohol-to-jet fuel upgrading cost reported in prior study of $\$ 0.1-1.8 / \mathrm{L}-\mathrm{Jet}-\mathrm{A}_{\text {eq. }}{ }^{37}$ The horizontal dashed lines represent the last 10-year (2009-2018) average selling price of the conventional jet fuel of $\$ 0.6 / \mathrm{L}-\mathrm{Jet}-\mathrm{A}$ at the refinery gate. ${ }^{36}$ The box and whisker plots show the results of Monte Carlo simulations.

Although, under the current state of technology, the $10 \% \mathrm{Pt} / \mathrm{C}$ catalyst achieves the lowest DMCO minimum selling price, this route may not have the greatest long-term potential. If all three catalysts can achieve comparable isoprenol-to-DMCO conversion rates, the Raney nickelbased hydrogenation process results in the lowest DMCO production cost because of the lower catalyst-loading rate and cost relative to other catalysts considered in this study (Table 1). This highlights the importance of achieving a near-theoretical yield of DMCO with a cheap metal catalyst at a low catalyst loading rate. Another area of incremental improvement is the cellulosic sugar production cost, which is the single most influential parameter in determining the minimium selling price of DMCO (Fig. 3). The sugar cost of $\$ 221 / \mathrm{bdt}$ in the optimal future case could be reduced to $\$ 213 /$ bdt by minimizing the transportation of the engineered biomass sorghum, selecting a variety with high carbohydrate content (70 wt\%) and low lignin (9.8 wt $\%)^{17}$, and optimizing yields and process conditions for sugar production. Field trial and compositional analysis data suggests that these are achievable, particularly in some highyielding non-photoperiod sensitive sorghum varieties. ${ }^{38}$ These improvements result in a $\$ 1.4 / \mathrm{L}-$ Jet-A eq minimum DMCO selling price of DMCO with the Raney nickel-based hydrogenation process. In this case, the sugar depot would need to be located near the sorghum field (trucking distance of $33 \mathrm{~km}$ or $\sim 20$ miles) and sugar yield must be increased to $98 \%$ of the theoretical yield at a low IL loading rate of $2.5 \mathrm{wt} \%$ and an enzyme loading rate of $7 \mathrm{mg}$ of protein per $\mathrm{g}$ of glucan (SI-Fig. S2). We find that, for each $\$ 0.01 / \mathrm{kg}$ decrease in sugar cost, the minimum selling price of DMCO is reduced by 3.7 to 11.9 cents/L-Jet-A $A_{\text {eq }}$ depending on the specific technological 
scenario (yield, residence time, upgrading yields). However, the sugar supply cost reduction is a challenge for a remote biorefinery as the sugar supply cost increases with an increase in the supply radius. Concentrated sugar ( $20 \%$ moisture content) transportation by truck is estimated to cost 7.6 cents per bone-dry metric ton per km traveled. This sugar supply cost has the potential to increase the minimum selling price of DMCO by 2.8 to 7.4 cents/L-Jet- $A_{\text {eq }}$ per 100 $\mathrm{km}$ increase of the supply radius from the sugar depot to the biorefinery. Long-distance transportation costs can be reduced by switching to rail or marine modes.

It is clear from our results that even the aggressive process-level improvements considered here (Table 1 and SI-Table S2) are not sufficient to reach parity with the last 10-year average selling price of jet fuel ${ }^{36}$ of $\$ 0.6 /$ L-Jet-A. This means that replacing Jet-A with at or near $100 \%$ DMCO will come at a substantial cost. However, if replacing petroleum-derived jet fuel is a priority and paraffinic bio-jet fuels require a blendstock like DMCO to achieve the necessary specifications (at, for example, a 30\% blend to avoid the use of petroleum-derived aromatics), it is conceivable that DMCO could garner a premium, particularly in markets where its high energy density is valuable. Although not considered in this study, lignin valorization can be a viable route to improving the economics of advanced biorefineries, ${ }^{2,22}$ and depending on the value of the lignin (either sold as a co-product or converted on-site), this may further reduce the minimum selling price for cellulosic sugars. Policy supports tied to biofuels' ability to mitigate GHG emissions is another important and potentially necessary option for achieving competitive prices in the near-term. 

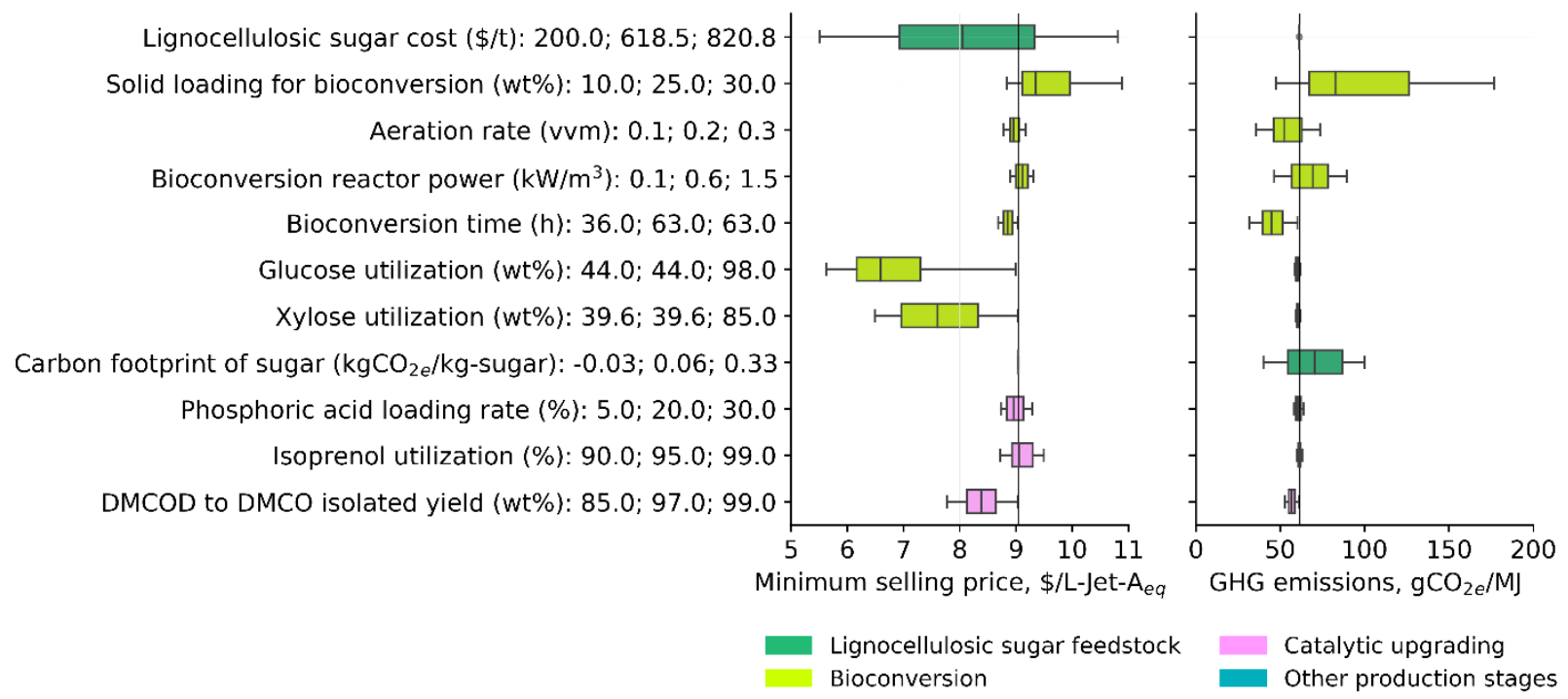

Fig. 3 Most significant process parameters requiring additional research and development efforts. DMCOD: 1,6-dimethyl-1,5-cyclooctadiene. This is a representative case considering the current state-of-technology and the $10 \% \mathrm{Pt} / \mathrm{C}$ catalyst for the hydrogenation process.

\subsection{Carbon Footprint of DMCO}

Utilizing a lignocellulosic sugar feedstock, the carbon footprint of DMCO is very likely to be lower than the footprint for conventional jet fuel, regardless of the scenario analyzed. In fact, counterintuitively, the GHG savings are less dependent on overall yields than the costs for two reasons: First, the sorghum biomass feedstock is expected to sequester carbon in the soil, resulting in a relatively low GHG footprint per unit of cellulosic sugar and consequently a modest GHG benefit from increased sugar-to-fuel yields. Second, any unutilized sugar from the bioconversion reactor is expected to be converted to biogas in the facility's anaerobic digester (which in turn reduces the need for on-site combustion of natural gas). Although some of the sugar not converted to isoprenol may instead go to side products, including $\mathrm{CO}_{2}$ and $\mathrm{H}_{2} \mathrm{O}$, or cell mass, the underlying assumption is that non-gaseous products will be available to microbes for 
conversion in the anaerobic digester. When combined, these mechanisms have a dampening effect on the GHG footprint.

For the current state-of-technology scenario, the soil organic carbon (SOC) sequestration potential of biomass sorghum, on average, of -0.46 metric tons of $\mathrm{CO}_{2 \mathrm{e}} / \mathrm{ha}^{20,21}$ and electricity generated onsite offset $18 \%$ and $44 \%$ of the total GHG emissions from DMCO production stages, respectively(Fig. 4-a). These reductions result in $31 \%, 11 \%$, and $28 \%$ lower carbon footprint of DMCO with $10 \% \mathrm{Pt} / \mathrm{C}$, Raney nickel, and $10 \% \mathrm{Pd} / \mathrm{C}$ catalysts, respectively. These differences are primarily due to differences in the DMCOD to DMCO conversion rates with the selected catalysts at present (Table 1). The GHG footprint of the current state-of-technology DMCO production route is, surprisingly, decreased by $10 \%$ when only glucose is utilized (Fig. 4a) because xylose-containing wastewater boosts biogas generated on-site, thus reducing natural gas input to the boiler. For the current state-of-technology, the likelihood of achieving a reduction in the GHG footprint relative to Jet-A is in the range of $43-44 \%$. When the isoprenol yield is increased to $90 \%$ of the theoretical yield, the carbon footprint of DMCO-relative to the current state-of-technology scenario-is increased by 1-2\% for the MVA pathway (Fig. 4-b) and is reduced by $9-12 \%$ for the MEP pathway (Fig. 4-c). This is simply a result of the MVA pathway's lower theoretical yield (31.87 g/100 g of sugar) and the fact that unutilized sugars were providing a co-benefit because of their downstream conversion to biogas. In contrast, the MEP pathway achieves a net GHG benefit when it reaches $90 \%$ of its higher theoretical yield (38.25 g/100 g of sugar) (see Table 1).

Net GHG contributions from the key production stages, including sugar feedstock production and bioconversion to isoprenol, can be reduced from $28 \%$ to $20 \%$ and $31 \%$ to $13 \%$ of the total 
emissions, respectively, when these processes are fully optimized. To reduce the GHG footprint of cellulosic sugars, sugar yields must be improved to (>90\%) using low ionic liquid (2.5\%) and enzyme (10 mg protein/g-glucan) loadings (Table 1). Importantly, the lower bioconversion time of $36 \mathrm{~h}$ in the optimal case reduces on-site electricity consumption to operate the aerobic bioconversion reactor (including agitation and sparging) (Fig. 4-a and d). However, the carbon footprint contribution from the onsite energy generation stage to the total GHG emissions is increased from $24 \%$ to $42 \%$ when the DMCO production process is improved from the current state (Fig. 4-a) to the optimal future case (Fig. 4-d). Essentially, as the conversion efficiency improves, less unconverted sugar remains in wastewater, thus reducing biogas yield during anaerobic digestion. With less biogas generated for use in the boiler, more external energy (natural gas) is required to meet the heat and electricity demands of the facility. In an integrated biomass-to-biofuel facility, more lignin and other organics are available for conversion and changes in biogas yield will have a smaller relative effect on heat/electricity generation potential, while a facility utilizing a relatively clean sugar stream does not have access to those renewable sources of energy. Despite these tradeoffs, the optimized case does result in a net reduction in the carbon footprint of DMCO by $79 \%$ relative to conventional jet fuel (Fig. 4-d). Based on the Monte Carlo simulation, the likelihood of achieving this optimal carbon footprint reduction is $15 \%$ (Fig. 4-d). As noted previously, additional improvements that reduce the energy input of bioconversion per unit of isoprenol produced will shrink the final GHG footprint of DMCO; this can include increased solids loading rate during bioconversion, decreasing the aeration rate (if yield is held constant) (Fig. 3 and SI-Fig. S4). Procuring cellulosic sugars with a lower GHG footprint and increasing the DMCOD to DMCO conversion rate are 
also viable strategies. For comparison, past studies ${ }^{2,37}$ reported GHG emissions reductions of different bio-jet fuel molecules (paraffins and naphthenes) relative to the conventional jet fuel are in the range of $57-105 \%$.

There is considerable uncertainty about how the sugar depot model would be implemented in practice, and the distances that sugar would need to be transported. These distances will not only impact the cost, but also the GHG emissions. We find that the carbon footprint of sugar is increased by $0.17 \mathrm{gCO}_{2 \mathrm{e}} / \mathrm{kg}$-sugar $/ \mathrm{km}$ of the supply radius if sugar is transported via a conventional diesel-powered truck. These transportation emissions will increase the carbon footprint of $\mathrm{DMCO}$ by $4.4 \mathrm{gCO}_{2 \mathrm{e}} / \mathrm{MJ} / 100 \mathrm{~km}$ of the supply radius for the current state of the technology and by $1.7 \mathrm{gCO}_{2 \mathrm{e}} / \mathrm{MJ} / 100 \mathrm{~km}$ of the supply radius for the optimal future case (because of higher yields in the optimal case). Of course, mode shifting from truck to rail can allow facilities to source sugar from a larger radius with minimal impact on emissions. The use of advanced fuel cell hybrid electric or fully electric trucks is another option for minimizing transportation emissions. ${ }^{39,40}$ Eliminating the use of natural gas for the boiler in favor of renewable resources, such as hog fuel (wood residue and sawmill wastes) or biogas sourced from dairy digesters, can also further reduce the GHG footprint of DMCO. For the optimal future case, we find that switching from natural gas to hog fuel increases the likelihood of a $79 \%$ reduction in GHG emissions relative to conventional fuel from $15 \%$ to $57 \%$. Sourcing electricity from renewable resources, either through strategic siting of facilities in renewablesdominated regions or through special purchase agreements with the local utility, is yet another option that may become increasingly attractive for facilities wishing to earn policy incentives for GHG mitigation. 
(a) Current state of technology

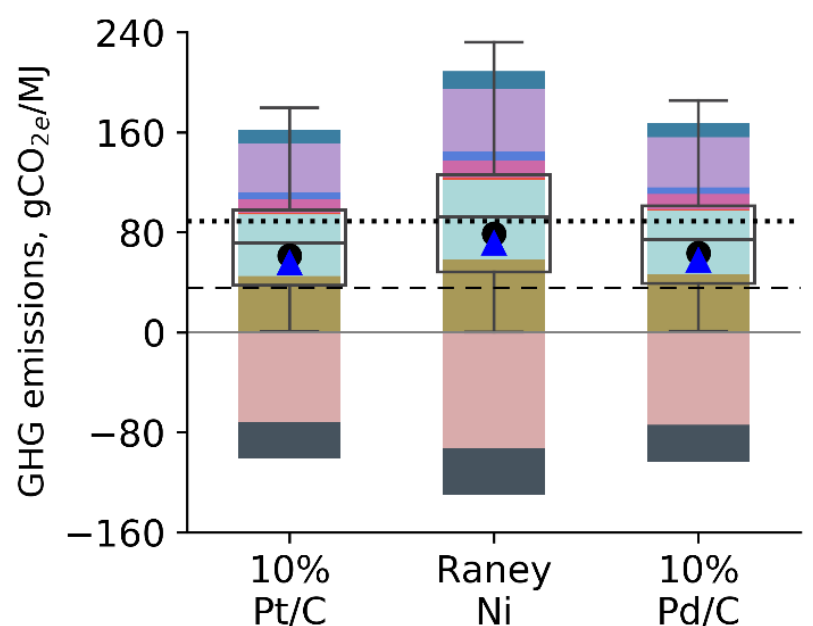

(c) Improved MEP pathway

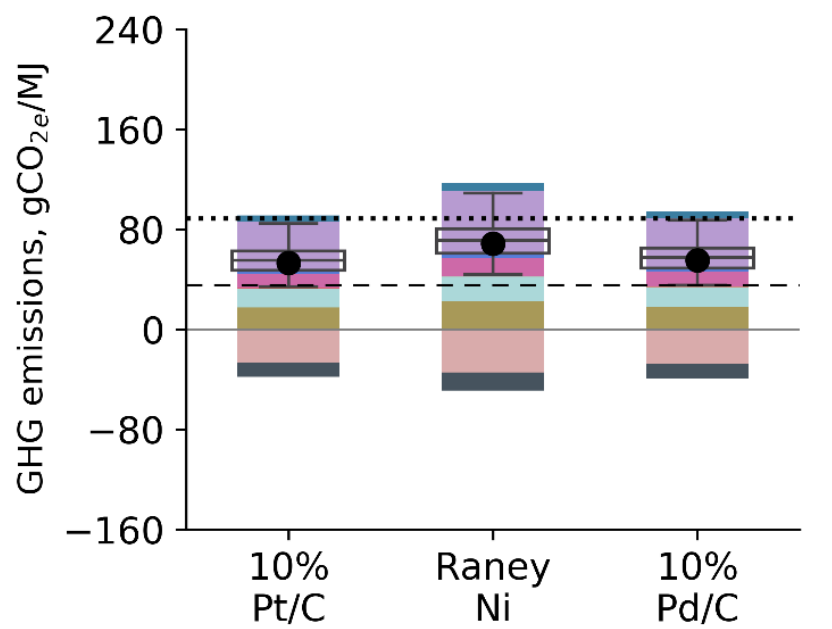

Carbon footprint of cellulosic sugar

Bioconversion

Recovery \& separation

Catalytic upgrading

Wastewater treatment

Onsite energy generation (b) Improved MVA pathway

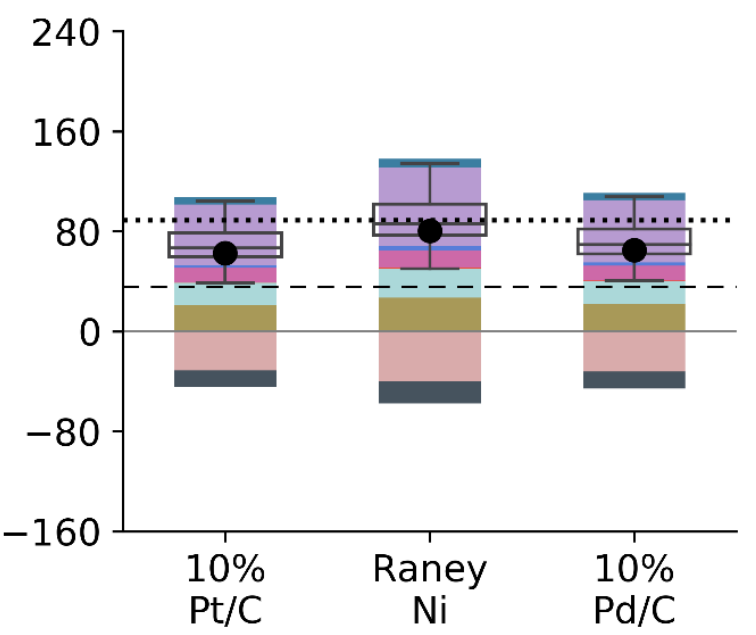

(d) Optimal future case

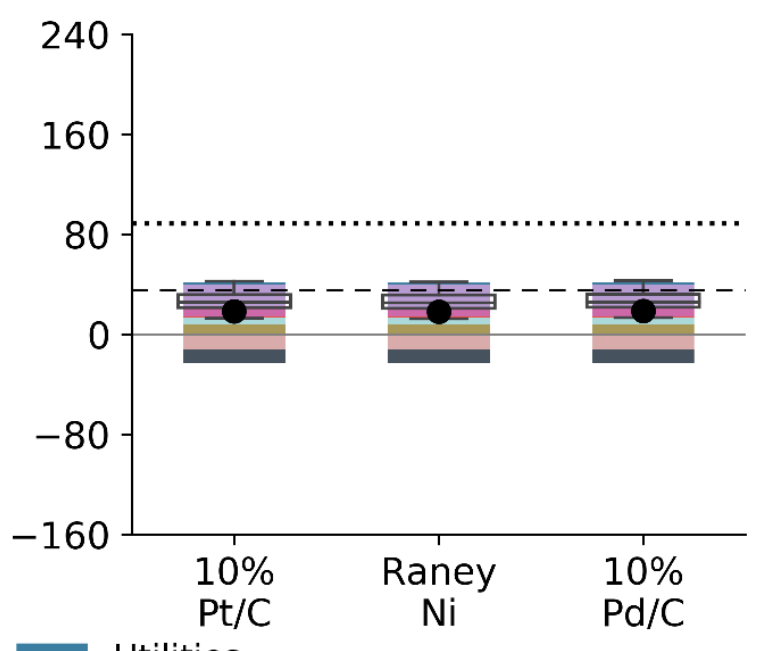

Utilities

Onsite electricity credits

Direct land use changes (dLUCs)

- Baseline carbon footprint

- Carbon footprint utilizing only glucose

Fig. 4 Greenhouse gas footprint of DMCO under different scenarios: (a) current state-oftechnology (SOT) with MVA pathway; (b) Improved MVA pathways with $90 \%$ of the theoretical isoprenol yield; (c) Improved MEP pathways with $90 \%$ of the theoretical isoprenol yield; and (d) 
Optimal future case with MVA pathway. The horizontal dotted and dashed lines, respectively, represent the carbon footprint of conventional jet fuel and the anticipated carbon footprint of $60 \%$ reduction relative to the conventional jet fuel. The box and whisker plots show the results of Monte Carlo simulations.

\section{Cost of Carbon Mitigation and Use-Phase Impacts of DMCO}

Reaching DMCO selling prices competitive with conventional Jet-A requires policy incentives. For the optimal future case-depending on the metal catalysts used for the hydrogenation process - the calculated cost of carbon mitigation (absent any supplemental policy support) is $\$ 331-786 / t-\mathrm{CO}_{2 \mathrm{e}}$ to achieve a minimum selling price of DMCO equal to $\$ 0.6 / \mathrm{L}-$ Jet-A $\mathrm{Aq}$ (10-year average price of conventional jet fuel at the refinery gate). ${ }^{36}$ Renewable DMCO can qualify as D3 “cellulosic biofuel” under the Renewable Fuel Standard (RFS) - as it achieves a carbon intensity reduction of at least $60 \%$ relative to petroleum fuel- resulting in Renewable Identification Numbers (RINs) worth an average value in 2020 of $\$ 1.32$ per RIN (which is equal to a gallon of ethanol-equivalent fuel) (SI-Table S4). Average RIN values alone do not enable DMCO to reach cost-parity with Jet-A even if the Raney nickel-based hydrogenation process is used and the full process is optimized. In this case, RIN values would need to be at least \$1.94, which is lower than the current price in 2021 of $\$ 2.39 /$ RIN. Alternatively, a lower RIN value of $\$ 0.78 /$ RIN (minimum value in 2020, SI-Table S4) is acceptable if DMCO is sold into a market where a Low Carbon Fuel Standard (LCFS) provides supplemental support, such as California. If the RIN value is near the average of $\$ 1.32$, an LCFS credit $\left(\$ 106.7 / \mathrm{t}-\mathrm{CO}_{2 \mathrm{e}}\right)$ close to typical California LCFS values $\left(\$ 141-219 / \mathrm{tCO}_{2 \mathrm{e}}\right)^{41}$ is sufficient to achieve cost-parity

So far, the energy density advantage of DMCO has not been incorporated in these calculations, except to adjust to ethanol or Jet- $A_{\text {eq }}$ values as needed. However, a $9.2 \%$ higher volumetric net 
heat of combustion relative to conventional Jet-A does offer use-phase advantages for aviation in addition to blending opportunities with paraffinic biofuels such as HEFA-Jet. The higher energy density of DMCO provides additional value to commercial aviation by increasing aircraft range and efficiency. Considering an extreme case of $100 \%$ drop-in replacement of conventional jet fuel with DMCO, an airline could save 46.5 liters of fuel per passenger $(10.3 \%$ reduction relative to Jet-A) in a typical international flight from San Francisco (SFO), USA, to London (LHR), UK. However, without policy supports, this efficiency advantage does not compensate for the $16 \%$ higher selling price for DMCO relative to the projected jet fuel price in 2050 of $\$ 1.22 / L$ (2020 U.S. dollars) (see Fig. 5). This highlights the importance of either lignin valorization (not considered in this work) or policy incentives for making renewable jet fuel competitive with the petroleum counterpart. Assuming a high jet fuel price in 2050 of $\$ 1.22 / \mathrm{L}-$ Jet-A (2020 U.S. dollars), airlines can save fuel cost over the entire flight range when $100 \%$ DMCO is utilized and the DMCO biorefineries receive RINs or LCFS credits (Fig. 5). Compared to a low oil price scenario, DMCO requires a combination of California LCFS and Federal RINs to outperform Jet-A on a cost basis. Regardless of future conventional jet fuel prices, we find a carbon footprint reduction of $0.14 \mathrm{~kg}$ per passenger per $\mathrm{km}$ when the DMCO production process is fully optimized. 


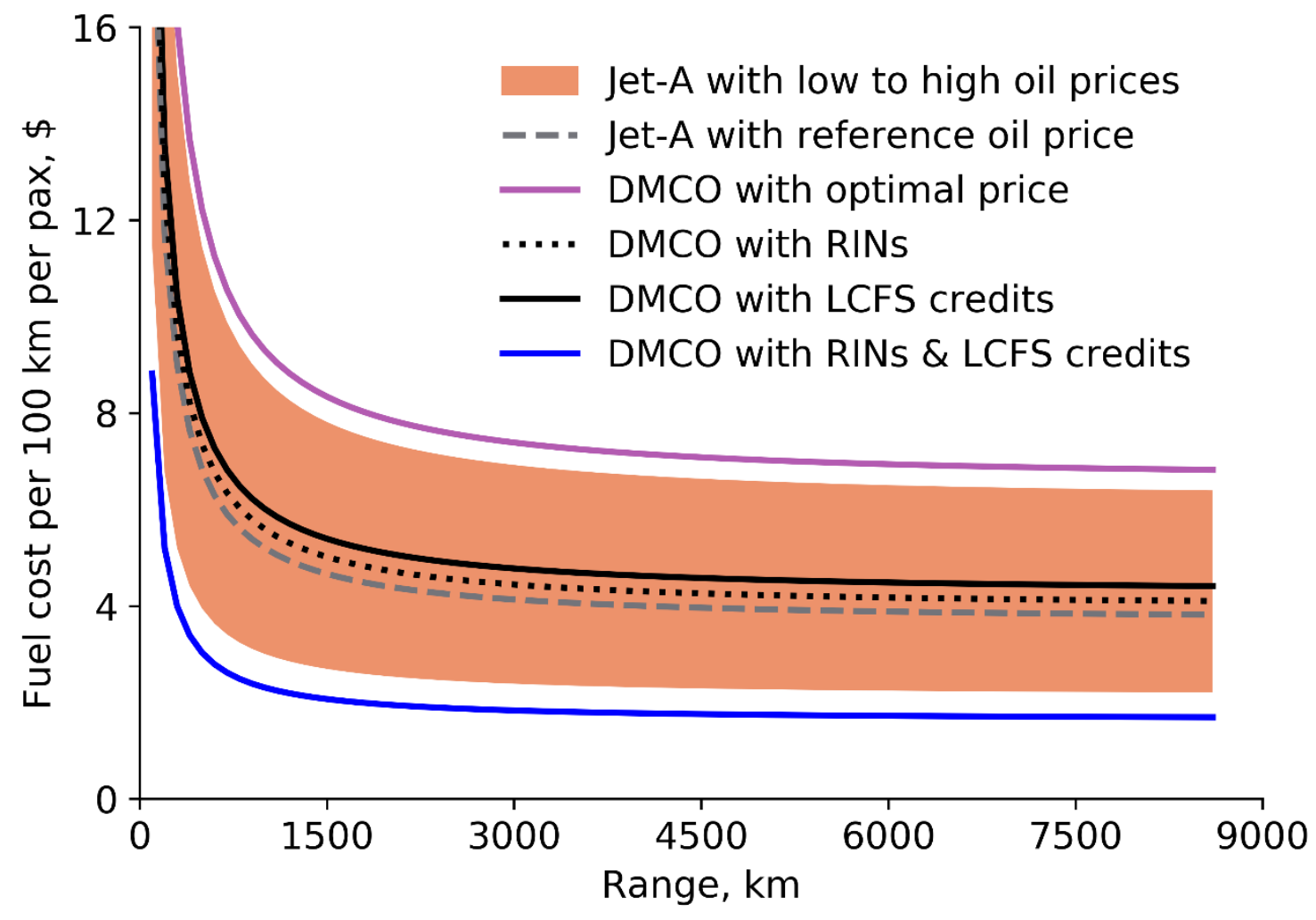

Fig. 5 Fuel cost savings over the range of aircraft per $100 \mathrm{~km}$ per passenger (Pax). This analysis includes the projected conventional jet fuel prices (2020 U.S. dollars) in 2050 of $\$ 0.42 / L$, $\$ 0.73 / \mathrm{L}$, and $\$ 1.22 / \mathrm{L}$ with low, reference, and high oil prices. ${ }^{35}$ This analysis includes the average LCFS and RIN credits of $\$ 199.07 / \mathrm{tCO}_{2 \mathrm{e}-\text { avoided }}$ and $\$ 1.32 / \mathrm{RIN}$ (for D3), respectively (SITable S4).

Our results highlight that DMCO could provide economic and carbon footprint benefits to the commercial aviation fleet, particularly if currently-available State and/or Federal policy supports are applied. However, this requires further research to optimize each step of the process, from feedstock composition through sugar and isoprenol yields and catalytic upgrading. If a sugar depot model is used, as modeled here, maximizing sugar yields and minimizing transportation distance to centralized fuel production facilities will be essential. Importantly, the optimal biorefinery requires more than $90 \%$ of theoretical maximum isoprenol yield at a short bioconversion time of $36 \mathrm{~h}$ and a sugar loading rate of at least $20 \mathrm{wt} \%$. Oxygen required for cell redox balancing could further be reduced by improving the biosynthetic 
pathway; this strategy can bring the life-cycle GHG footprint down because the aeration rate substantially alters the energy demand of the facility. The catalytic upgrading stage requires further research to ensure low metal catalyst-loading and low upfront catalyst costs. The development of a heterogeneous catalyst with a long lifetime would significantly reduce the metal catalyst cost. A transition to a continuous process for DMCOD synthesis is also required. If all these improvements can be achieved DMCO has a potential to serve as a highperformance, energy-dense blendstock that both reduces GHG emissions itself and also enables an acceleration in the adoption of more common paraffinic sustainable aviation fuels.

\section{Conflicts of interest}

There are no conflicts to declare.

\section{Acknowledgements}

This work was part of the DOE Joint BioEnergy Institute (http://www.jbei.org) supported by the U.S. Department of Energy, Office of Science, Office of Biological and Environmental Research, through contract DE-AC02-05CH11231 between Lawrence Berkeley National Laboratory and the U.S. Department of Energy. This study was also supported by the U.S. Department of Energy, Energy Efficiency and Renewable Energy, Bioenergy Technologies Office. BGH acknowledges funding from the Office of Naval Research Bioengineering and Biomanufacturing 
Program. The United States Government retains and the publisher, by accepting the article for publication, acknowledges that the United States Government retains a nonexclusive, paid-up, irrevocable, worldwide license to publish or reproduce the published form of this manuscript, or allow others to do so, for United States Government purposes.

\section{References}

(1) Bills, A.; Sripad, S.; Fredericks, W. L.; Singh, M.; Viswanathan, V. Performance Metrics Required of Next-Generation Batteries to Electrify Commercial Aircraft. ACS Energy Lett. 2020, 5, 663-668.

(2) Baral, N. R.; Kavvada, O.; Mendez-Perez, D.; Mukhopadhyay, A.; Lee, T. S.; Simmons, B. A.; Scown, C. D. Techno-economic analysis and life-cycle greenhouse gas mitigation cost of five routes to bio-jet fuel blendstocks. Energy Environ. Sci. 2019, 12, 807-824.

(3) Muldoon, J. A.; Harvey, B. G. Bio-Based Cycloalkanes: The Missing Link to HighPerformance Sustainable Jet Fuels. ChemSusChem 2020, 13, 5777-5807.

(4) Graham, J. L.; Striebich, R. C.; Myers, K. J.; Minus, D. K.; Harrison, W. E. Swelling of nitrile rubber by selected aromatics blended in a synthetic jet fuel. Energy Fuels 2006, 20, 759765.

(5) Wang, W.-C.; Tao, L. Bio-jet fuel conversion technologies. Renewable and Sustainable Energy Reviews 2016, 53, 801-822.

(6) Rosenkoetter, K. E.; Kennedy, C. R.; Chirik, P. J.; Harvey, B. G. [4 + 4]-cycloaddition of isoprene for the production of high-performance bio-based jet fuel. Green Chem. 2019, 21, 5616-5623.

(7) Whited, G. M.; Feher, F. J.; Benko, D. A.; Cervin, M. A.; Chotani, G. K.; McAuliffe, J. C.; LaDuca, R. J.; Ben-Shoshan, E. A.; Sanford, K. J. TECHNOLOGY UPDATE: Development of a gas-phase bioprocess for isoprene-monomer production using metabolic pathway engineering. Industrial Biotechnology 2010, 6, 152-163.

(8) Ye, L.; Yu, H. Efforts toward industrial biosynthesis of isoprene. In Consequences of Microbial Interactions with Hydrocarbons, Oils, and Lipids: Production of Fuels and Chemicals; Lee, S. Y., Ed.; Springer International Publishing: Cham, 2017; pp. 1-20.

(9) Riazi, B.; Karanjikar, M.; Spatari, S. Renewable Rubber and Jet Fuel from Biomass: Evaluation of Greenhouse Gas Emissions and Land Use Trade-offs in Energy and Material Markets. ACS Sustain. Chem. Eng. 2018, 6, 14414-14422.

(10) US3792104A. Manufacture of isoprene. https://patents.google.com/patent/US3792104A/en (accessed Jan 22, 2020). 
(11) US10273506B2. Host cells and methods for producing isopentenol from mevalonate. https://patents.google.com/patent/US10273506B2/en (accessed Jan 22, 2020).

(12) Kang, A.; Mendez-Perez, D.; Goh, E.-B.; Baidoo, E. E. K.; Benites, V. T.; Beller, H. R.; Keasling, J. D.; Adams, P. D.; Mukhopadhyay, A.; Lee, T. S. Optimization of the IPPbypass mevalonate pathway and fed-batch fermentation for the production of isoprenol in Escherichia coli. Metab. Eng. 2019, 56, 85-96.

(13) George, K. W.; Thompson, M. G.; Kang, A.; Baidoo, E.; Wang, G.; Chan, L. J. G.; Adams, P. D.; Petzold, C. J.; Keasling, J. D.; Lee, T. S. Metabolic engineering for the high-yield production of isoprenoid-based $C_{5}$ alcohols in E. coli. Sci. Rep. 2015, 5, 11128.

(14) Baral, N. R.; Kavvada, O.; Mendez-Perez, D.; Mukhopadhyay, A.; Lee, T. S.; Simmons, B.; Scown, C. D. Greenhouse Gas Footprint, Water-Intensity, and, Production Cost of BioBased Isopentenol as a Renewable Transportation Fuel. ACS Sustain. Chem. Eng. 2019.

(15) Morris, D. M.; Quintana, R. L.; Harvey, B. G. High-Performance Jet Fuels Derived from Bio-Based Alkenes by Iron-Catalyzed [2+2] Cycloaddition. ChemSusChem 2019, 12, 1646-1652.

(16) Xu, F.; Sun, J.; Konda, N. V. S. N. M.; Shi, J.; Dutta, T.; Scown, C. D.; Simmons, B. A.; Singh, S. Transforming biomass conversion with ionic liquids: process intensification and the development of a high-gravity, one-pot process for the production of cellulosic ethanol. Energy Environ. Sci. 2016, 9, 1042-1049.

(17) Magurudeniya, H. D.; Baral, N. R.; Rodriguez, A.; Scown, C. D.; Dahlberg, J.; Putnam, D.; George, A.; Simmons, B. A.; Gladden, J. M. Use of ensiled biomass sorghum increases ionic liquid pretreatment efficiency and reduces biofuel production cost and carbon footprint. Green Chem. 2021, 23, 3127-3140.

(18) Kennedy, C. R.; Zhong, H.; Macaulay, R. L.; Chirik, P. J. Regio- and Diastereoselective Iron-Catalyzed [4+4]-Cycloaddition of 1,3-Dienes. J. Am. Chem. Soc. 2019, 141, 85578573.

(19) US10981846B1. Producing cyclic fuels from conjugated diene. https://patents.google.com/patent/US10981846B1/en (accessed May 28, 2021).

(20) Gautam, S.; Mishra, U.; Scown, C.; Zhang, Y. Sorghum biomass production in the continental United States and its potential impacts on soil organic carbon and nitrous oxide emissions. Glob Change Biol Bioenergy 2020.

(21) DOE. 2016 Billion-Ton Report, Volume 2: Environmental Sustainability Effects of Select Scenarios from Volume 1 https://www.energy.gov/eere/bioenergy/downloads/2016billion-ton-report-volume-2-environmental-sustainability-effects (accessed Jan 1, 2020).

(22) NREL. Process Design and Economics for the Conversion of Lignocellulosic Biomass to Hydrocarbon Fuels and Coproducts:2018 Biochemical Design Case Update https://www.nrel.gov/docs/fy19osti/71949.pdf (accessed Jul 15, 2019).

(23) Catalyst Cost Estimating Tool Significantly Improves Research Efficiency | News | NREL 
https://www.nrel.gov/news/program/2019/catalyst-cost-estimating-tool-significantlyimproves-research-efficiency.html (accessed Jan 23, 2020).

(24) Humbird, D.; Davis, R.; Tao, L.; Kinchin, C.; Hsu, D.; Aden, A.; Schoen, P.; Lukas, J.; Olthof, B.; Worley, M.; et al. Process Design and Economics for Biochemical Conversion of Lignocellulosic Biomass to Ethanol; NREL/TP-5100-47764; National Renewable Energy Laboratory, 2011.

(25) Neupane, B.; Konda, N. V. S. N. M.; Singh, S.; Simmons, B. A.; Scown, C. D. Life-Cycle Greenhouse Gas and Water Intensity of Cellulosic Biofuel Production Using Cholinium Lysinate Ionic Liquid Pretreatment. ACS Sustain. Chem. Eng. 2017, 5, 10176-10185.

(26) US LCA Database. LCA Collaboration Server https://www.Icacommons.gov/lcacollaboration/search/page=1\&group=National_Renewable_Energy_Laboratory (accessed Jul 23, 2019).

(27) ECOINVENT. Ecoinvent LCl database https://www.ecoinvent.org/ (accessed Jul 22, 2019).

(28) Argonne GREET Model https://greet.es.anl.gov/ (accessed Jan 25, 2021).

(29) ESRG. Carbon Footprints of Recycled Solvents https://esrg.de/media/PDF/Study_print_090514.pdf (accessed Jan 5, 2020).

(30) Kang, A.; Meadows, C. W.; Canu, N.; Keasling, J. D.; Lee, T. S. High-throughput enzyme screening platform for the IPP-bypass mevalonate pathway for isopentenol production. Metab. Eng. 2017, 41, 125-134.

(31) Shi, J.; George, K. W.; Sun, N.; He, W.; Li, C.; Stavila, V.; Keasling, J. D.; Simmons, B. A.; Lee, T. S.; Singh, S. Impact of Pretreatment Technologies on Saccharification and Isopentenol Fermentation of Mixed Lignocellulosic Feedstocks. Bioenerg. Res. 2015, 8, 1004-1013.

(32) Kang, A.; George, K. W.; Wang, G.; Baidoo, E.; Keasling, J. D.; Lee, T. S. Isopentenyl diphosphate (IPP)-bypass mevalonate pathways for isopentenol production. Metab. Eng. 2016, 34, 25-35.

(33) Burzlaff, M. Aircraft Fuel Consumption-Estimation and Visualization. Aircraft Design and Systems Group (AERO), Department of Automotive and Aeronautical Engineering, Hamburg University of Applied Sciences. 2017. https://www.fzt.hawhamburg.de/pers/Scholz/arbeiten/TextBurzlaff.pdf (accessed Feb 4, 2020).

(34) Schäfer, A. W.; Evans, A. D.; Reynolds, T. G.; Dray, L. Costs of mitigating CO2 emissions from passenger aircraft. Nat. Clim. Chang. 2015, 6, 412-417.

(35) EIA. Annual Energy Outlook 2020. U.S. Energy Information Administration (EIA). https://www.eia.gov/outlooks/aeo/ (accessed Jan 11, 2021).

(36) E I A. U.S. Kerosene-Type Jet Fuel Wholesale/Resale Price by Refiners https://www.eia.gov/dnav/pet/hist/LeafHandler.ashx?n=PET\&s=EMA_EPJK_PWG_NUS_ DPG\&f=M (accessed Feb 4, 2020). 
(37) NREL. Review of Biojet FuelConversion Technologies https://www.nrel.gov/docs/fy16osti/66291.pdf (accessed Feb 5, 2020).

(38) Yang, M.; Dahlberg, J.; Baral, N.R.; Putnam, D.; Scown, C.D. Identifying Forage Sorghum Ideotypes for Advanced Biorefineries. ACS Sustain. Chem. Eng. 2021. DOI: 10.1021/acssuschemeng.1c01706.

(39) Liu, X.; Reddi, K.; Elgowainy, A.; Lohse-Busch, H.; Wang, M.; Rustagi, N. Comparison of well-to-wheels energy use and emissions of a hydrogen fuel cell electric vehicle relative to a conventional gasoline-powered internal combustion engine vehicle. Int. J. Hydrogen Energy 2020, 45, 972-983.

(40) Baral, N. R.; Asher, Z. D.; Trinko, D.; Sproul, E.; Quiroz-Arita, C.; Quinn, J. C.; Bradley, T. $\mathrm{H}$. Biomass feedstock transport using fuel cell and battery electric trucks improves lifecycle metrics of biofuel sustainability and economy. J. Clean. Prod. 2021, 279, 123593.

(41) CARB. Weekly LCFS Credit Trading Activity Reports https://ww3.arb.ca.gov/fuels/lcfs/credit/Irtweeklycreditreports.htm (accessed Nov 6, 2019). 